\title{
LOW-FRICTION ARTHROPLASTY OF THE HIP FOR THE FAILURES OF PREVIOUS OPERATIONS
}

\author{
Joseph A. Dupont and John Charnley, Wrightington, England \\ From the Centre for Hip Surgery, Wrightington Hospital, Wigan, Lancashire
}

This report concerns 217 low-friction arthroplasties using high-density polyethylene for the acetabular component which were performed between November 1962 and April 1969 for the failures of previous hip operations in 203 patients. In contrast with the previous paper in which the results of primary operations by this technique were considered (page 61), the present analysis relates to cases which were technically much more difficult as well as more prone to infection.

No case has been included in which the follow-up was less than one year. Twenty-three patients have been followed up for five or six years and one for seven years. The numerous cases of revision after the earlier use of Teflon for the acetabular component have all been excluded.

\section{MATERIAL}

The study of the 217 arthroplasties in 203 patients is based on routine records of the findings before operation and at annual attendances. The numerical method of estimating pain, movement and function before and after operation resembles the code of Merle d'Aubigné and Postel (1954) and was described in the previous paper (page 62).

In order to preserve the size of sub-groups, the material was broken down into only three groups: "osteotomies", "prostheses" and "miscellaneous". There were 121 osteotomies in 116 patients, and fifty-one prostheses in forty-nine patients. Forty-five hips with miscellaneous disorders in forty patients included seventeen cup arthroplasties, nine pseudarthroses, nine arthrodeses and ten total replacements of types not used in this Centre. It is perhaps unfortunate that the cup arthroplasties were included in this group because their conversion is by far the easiest; if the hip is mobile and the original approach that of Smith-Petersen, the operation is hardly more difficult than a primary intervention.

Diagnosis-With regard to the conditions for which the previous operations had been performed, osteoarthrosis (182) greatly outnumbered all others. Fractured neck of femur (forty-one) was next in frequency. There were only eighteen failed operations for rheumatoid arthritis, a proportion much less than that of rheumatoid arthritis to osteoarthrosis in our series of primary interventions.

\section{TECHNIQUES}

The lateral exposure of the hip joint proved invaluable. None of the cup arthroplasties or femoral head replacements had been done through the lateral approach, so that the new incision was at some distance from the old scar. In the case of failed osteotomy, where a lateral exposure had usually been employed, any difficulty in finding the tissue plane between fascia lata and greater trochanter was compensated for by the ease of removal of the metallic appliance. Generally speaking, conversion of an osteotomy is not difficult unless gross inward displacement is present; the capsule of the joint is usually normal, making dislocation less difficult.

The most difficult implant to replace is the Moore prosthesis because: 1) it is often difficult to detach a greater trochanter of optimum size and shape; 2) the prosthesis is often very difficult to extract even when loose in the medullary canal; and 3) the track left in the 
medullary canal is often lined by fibrous tissue which has to be curetted away to permit bonding of the fresh cement to bone. This new cement bond is not as good as in primary intervention where a rough surface of freshly cut cancellous bone is present rather than smooth bone.

It is of great importance that the upper end of the femur should be adequately mobilised from the side wall of the pelvis if there is much limitation of movement before operation. Combined with detachment of the greater trochanter, this mobilisation greatly facilitates entry to the medullary canal and avoids the stem of the prosthesis emerging from the shaft, a common complication in difficult operations with inadequate exposure. Full mobilisation of the upper femur necessitates division of the psoas tendon and inferior capsule, combined in many cases with avulsion of the remaining adhesions by direct lateral traction. In attempting these difficult exposures it is most important to avoid forcible outward rotation lest a spiral fracture of the shaft of the femur is produced, for example through screw holes left after removal of

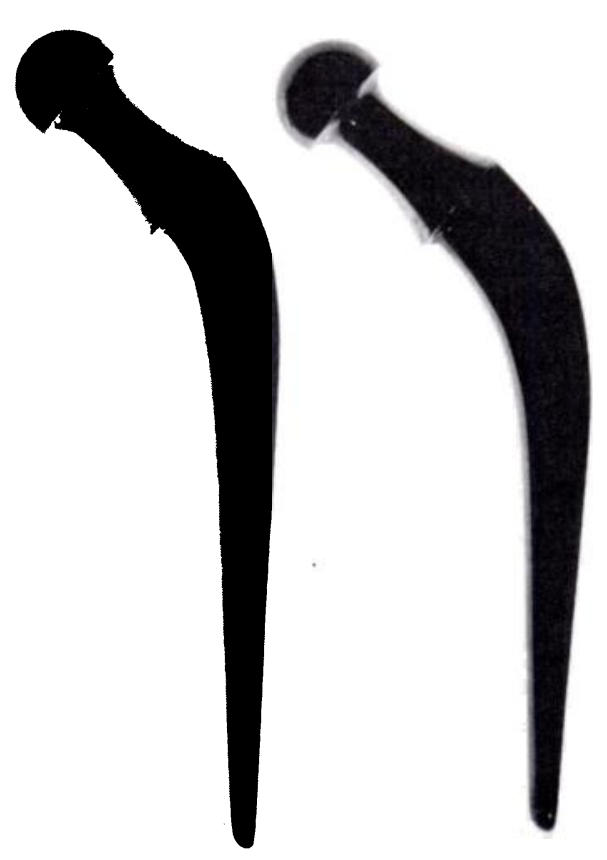

FIG. 1

The profiles of the straight stem (left $)$ and standard prostheses (right). an osteotomy plate. When the neck of the femur is absent, or after osteotomy when the shaft has been displaced medially, the straight stem model of prosthesis is advisable (Fig. 1). This prosthesis differs from the standard one in not having a curve to accommodate the calcar, as needed in a primary intervention when the neck is sectioned at mid-cervical level.

Conversion after osteotomy - A special difficulty after osteotomy is inability to extract screws, which often break off. Rather than produce a number of trephine holes through the shaft, during perhaps an hour of assault on the femur before the start of the reconstruction, we no longer attempt to remove broken screws. We prefer to break them in the medullary canal, using a long screwdriver hammered down the canal. With Vitallium screws this is fortunately quite easy. It is a theoretical disadvantage that pieces of chrome-cobalt screws should remain in the canal in contact with the stainless steel prosthesis; so far we have not had trouble, no doubt because the screws are insulated with cement (Figs. 2 and 3).

In order to strike the medullary canal of the femur five or six inches below the upper end in the course of revision of an osteotomy with gross medial displacement of the shaft, it is usually advisable not to try to enter the medullary canal through the open end of the neck of the femur. To attempt this may result in the stem of the prosthesis emerging through the lateral cortex where the original plate for internal fixation was placed, or it can result in marked valgus of the stem of the prosthesis. In grossly displaced osteotomies it is advisable to drill through the medial cortex of the stump of femoral neck and aim directly for the patella, watching the axis of the femur in two planes. Finding the medullary canal is greatly facilitated by using the straight "taper-pin reamer"; only when the medullary canal is discovered is this straight "canal seeker" changed for the femoral broaches. Full mobilisation of the upper end of the femur is essential, and it may be necessary to palpate the shaft both laterally and medially through the vasti so as to keep inside the femur without the use of radiographic control.

Conversion after femoral head replacement-Osseous or fibrous tissue in the large aperture of 
a Moore prosthesis can offer great resistance to extraction. It is useless to try to extract this type of prosthesis by a hook and inertia hammer, working only from above. The best way is to expose the upper end of the femur by dividing the psoas tendon and other attachments, and to avulse fibrous and scar tissue sufficiently to allow its displacement completely out of the wound. The femur is then adducted across the body and fully rotated outwards, the patient being supine on the table. The medial margin of the collar of the prosthesis becomes accessible, and with an engineer's cold chisel under the collar at this point, heavy hammer blows are directed upwards in the axis of the femur. Under this attack the prosthesis may be knocked out, bringing with it the contents of the upper foramen. If heavy blows fail to dislodge the prosthesis it is necessary to divide the tissue in the upper foramen lest continued blows should fracture the anterior or posterior wall of the upper end of the femur. An osteotome 12 millimetres wide with a wafer-thin blade is passed in front and behind the upper part of the stem just below the collar. This procedure is greatly facilitated by the previous elevation of the greater trochanter. Curettage of all fibrous tissue lining the track demands the use of a long-handled sharp curette with a small spoon.

Despite the fact that the stem of a Moore prosthesis is usually longer than that of a Charnley component, it is important always to drive the "straight taper-pin reamer" through the end of the track, because the blind end fills with blood which otherwise cannot escape into the marrow cavity. Alternatively a hole through the lateral cortex can be drilled for the same purpose.

Theoretically, in order to conserve length of the limb, a special prosthesis with a long neck should be advantageous when the femoral neck is missing. We have not found this advisable, even though shortening is invited when the prosthesis is sunk to full depth. Some deliberate shortening is indeed an advantage, because it favours good contact of the trochanter with the lateral surface of the femur and so helps to avoid fibrous union, which is seriously threatened if the trochanter only just touches its original site. It is important to have no cement on the cut surface of femur where it is hoped the trochanter will unite. Rather slow rehabilitation of these patients is advisable in the interests of bony union, and if any difficulty is encountered three weeks of abduction in bed are strongly recommended.

Previous cement in the medullary canal-Replacing cemented prostheses of Thompson type is not difficult with the appropriate instruments. A long 6-millimetre drill is first passed down the cement track to open the end into the medullary canal. This is followed by a series of "taper-pin reamers" held in a slow-speed power drill to open up the track. These reamers can be made to cut sideways in the coronal plane. No attempt is made to extract all the old cement if it is firm in the bone, and fresh cement is introduced prior to inserting the new prosthesis. Frequently the straight narrow-stem prosthesis is advisable to allow room for additional cement, but if the patient is heavy or relatively young and vigorous the straight thick-stem prosthesis should be used.

The new cement may need to be softer in consistency than usual. Absorption of monomer with transient fall of blood pressure is not likely because the old cement blocks its access to the circulation.

Conversion after arthrodesis-After elevation of the trochanter the neck of the femur must be sectioned in situ and the acetabulum excavated, at first with gouges and finally with the standard deepening and expanding reamers (Figs. 4 and 5). It is important in these cases to define the anterior limit of the acetabulum by passing a Hohmann retractor over the pubic ramus with its tip just inside the pelvis. In the one case of ischio-femoral arthrodesis in the series excision of the bone graft posed no problem (Figs. 6 and 7).

Conversion after pseudarthrosis-With the lateral access this presents no special problem other than adequate mobilisation of the femur. Preliminary traction to restore length has not been used; length is obtained at operation by division of whatever structures are taut, notably the psoas tendon and inferior capsule (Figs. 8 to 11 ).

VOL. 54 B, NO. 1, FEBRUARY 1972 
The high position of the greater trochanter can pose problems, though frequently these are not as difficult as anticipated. Section of the superior capsule and all fibrous attachments

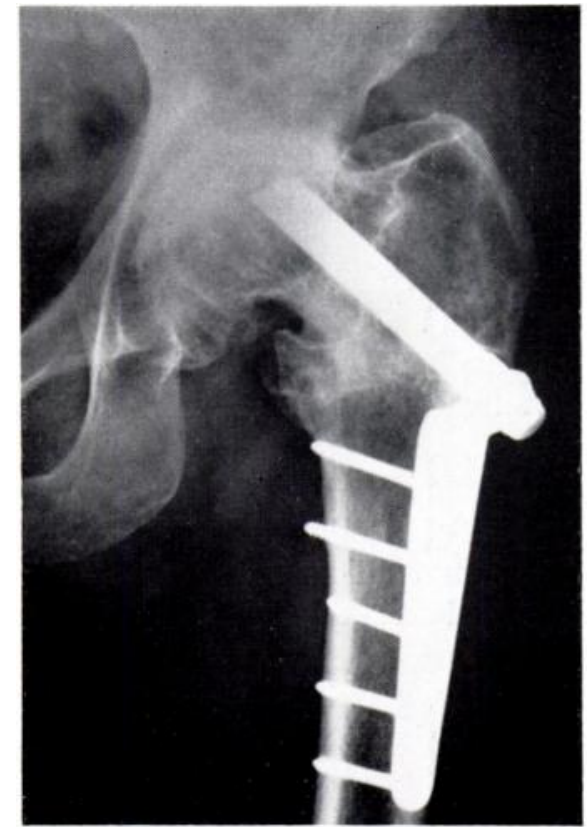

FIG. 2

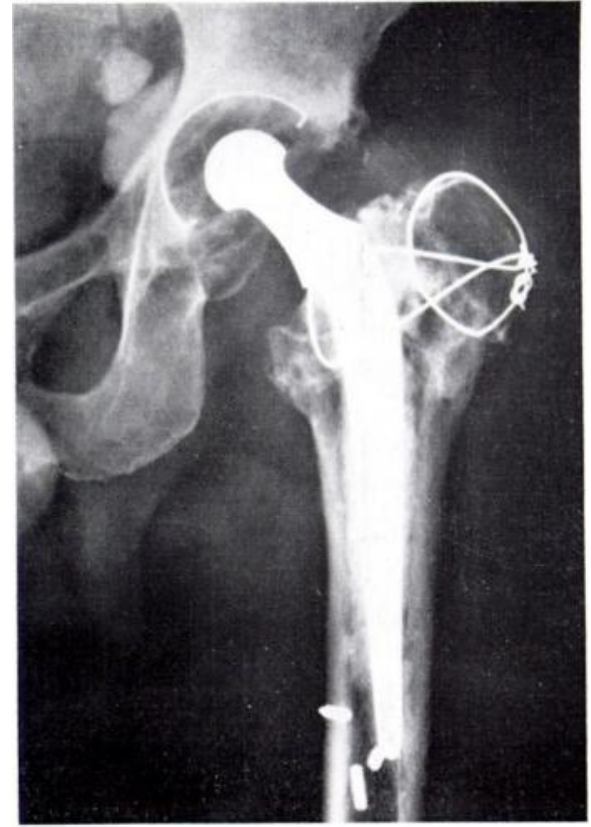

FIG. 3

Figure 2-Failed osteotomy before conversion. Figure 3--.The same case after conversion showing fragments of cobalt-chromium screws.

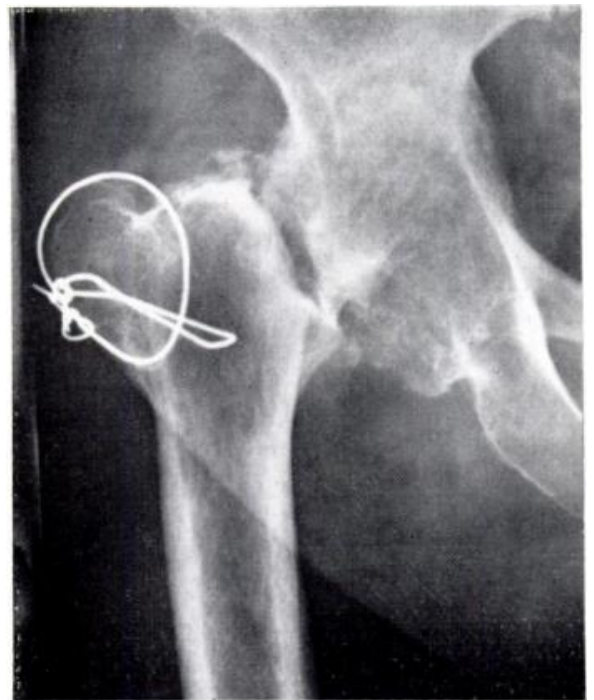

FiG. 4

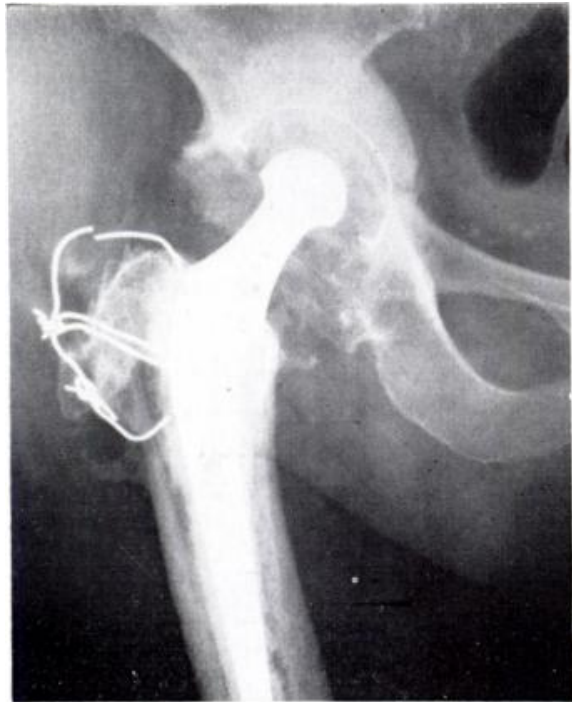

FiG. 5

Figure 4-Arthrodesis of a hip with non-union of a spontaneous fracture of the femoral neck. Figure 5-The same case after conversion to low-friction arthroplasty.

may be required to bring the trochanter down to an appropriate level. In order to facilitate union of the greater trochanter some shortening of the limb is advisable. 


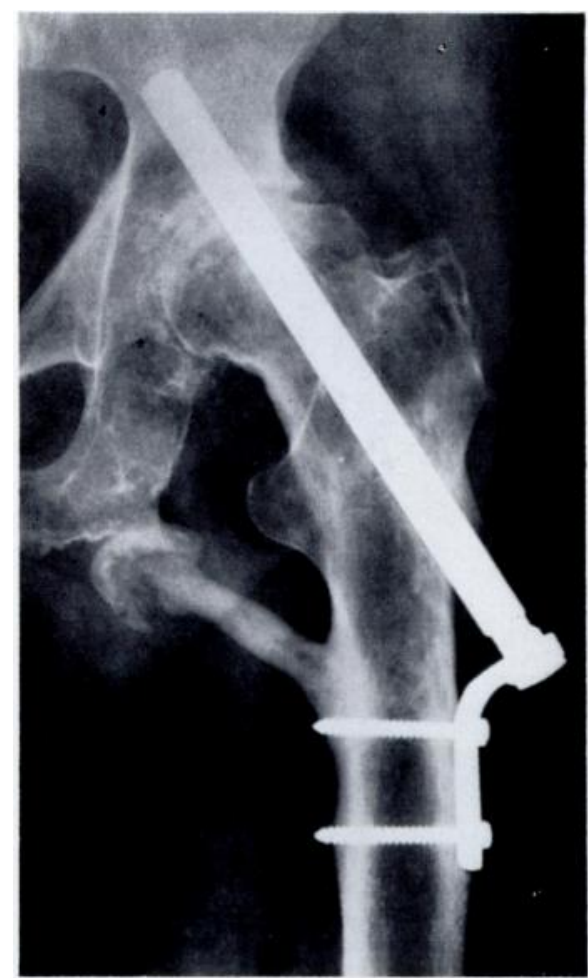

Fig. 6

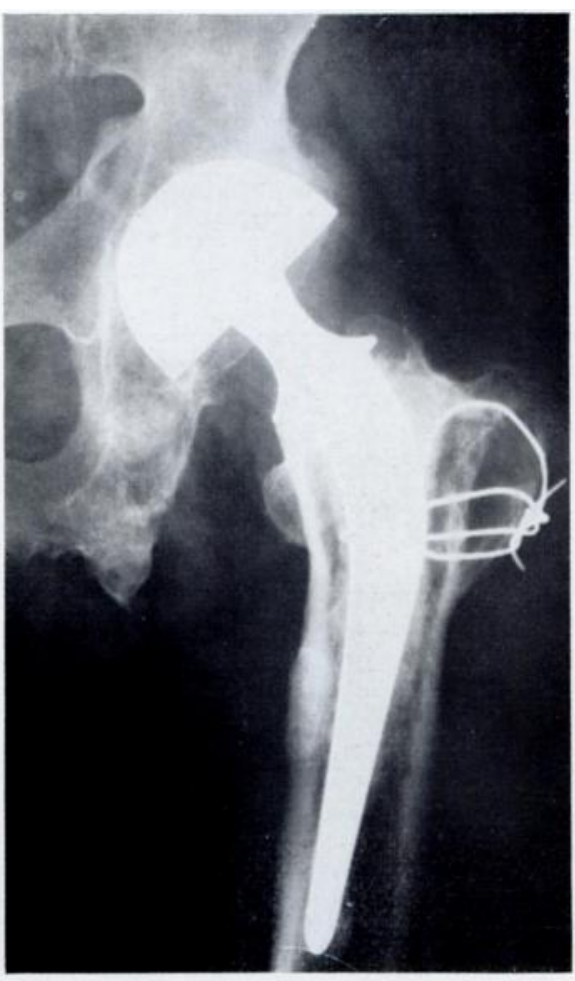

Fig. 7

Figure 6-A case of ischio-femoral arthrodesis. Figure 7-The same case after conversion to a "press-fit" type of low-friction arthroplasty.

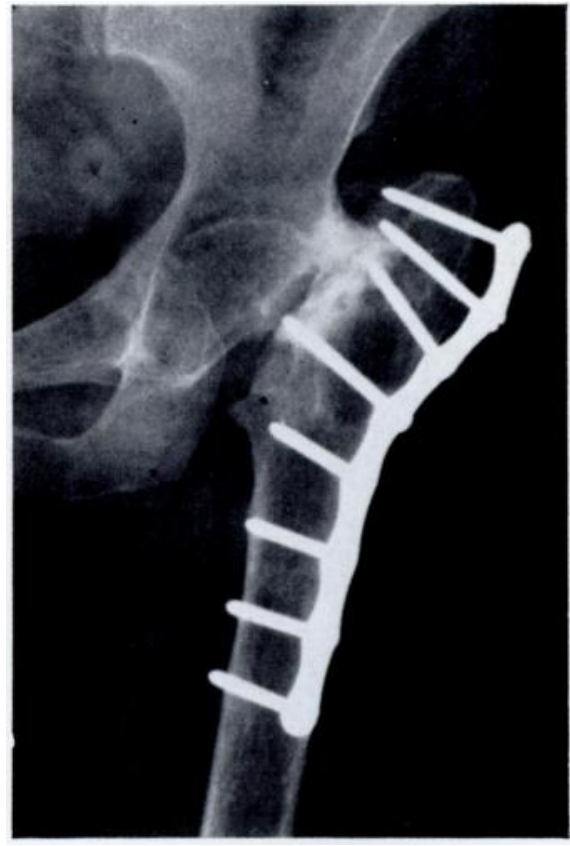

Fig. 8

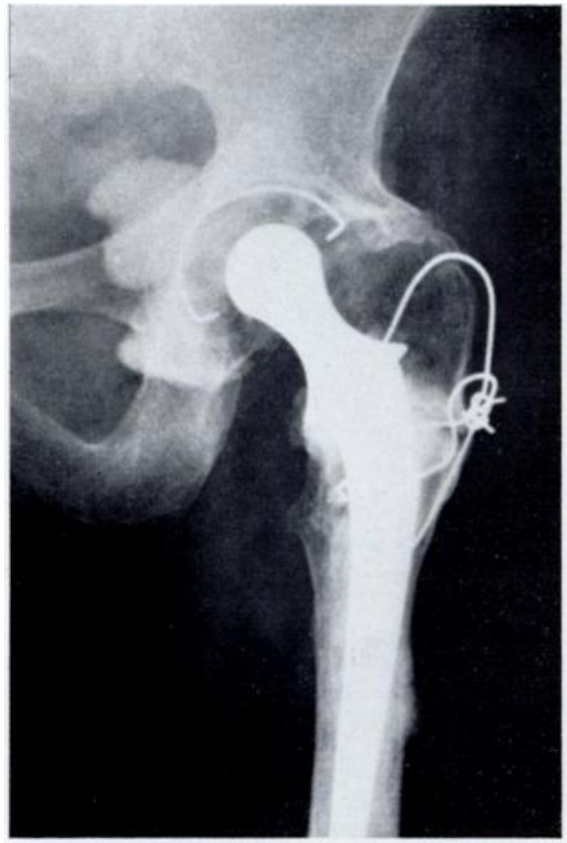

FIG. 9

Figure 8-A case of resection-angulation pseudarthrosis. Figure 9-The same case after conversion to low-friction arthroplasty.

VOL. 54 B, No. 1, FEBRUARY 1972 


\section{COMPLICATIONS}

After these difficult secondary interventions a higher rate of complication could be expected but has proved surprisingly low in comparison with the primary interventions reported in the previous paper (page 61 ).

Pulmonary embolism-There were two deaths $(0.8$ per cent $)$ due to massive embolism during the immediate post-operative period; both were proved at necropsy. In addition there were

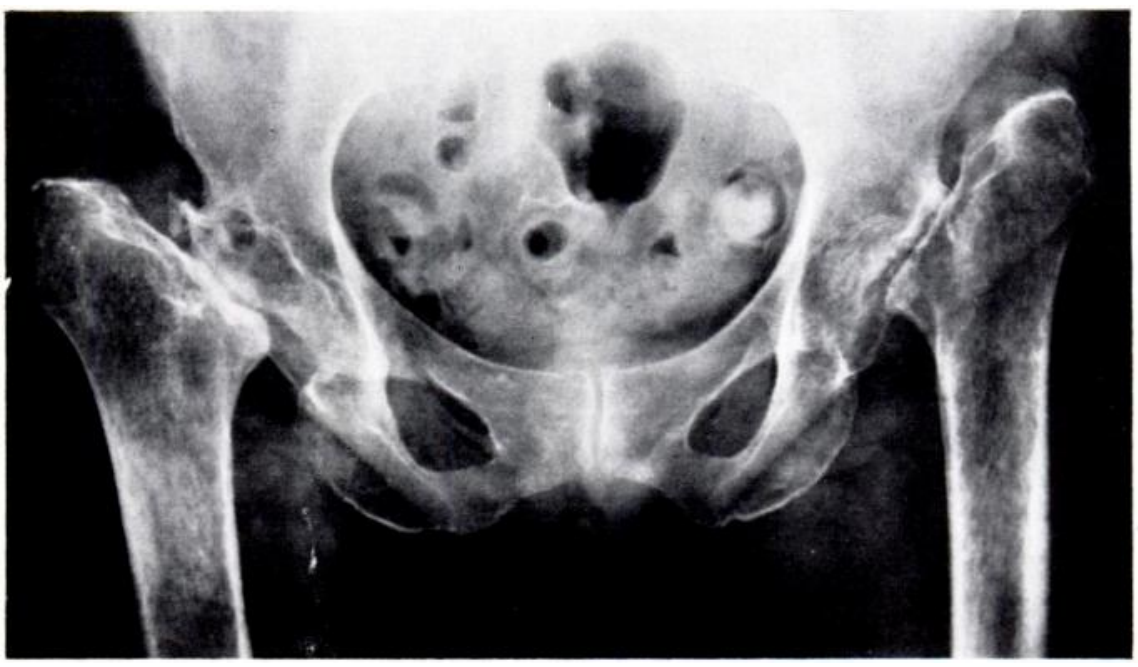

FiG. 10

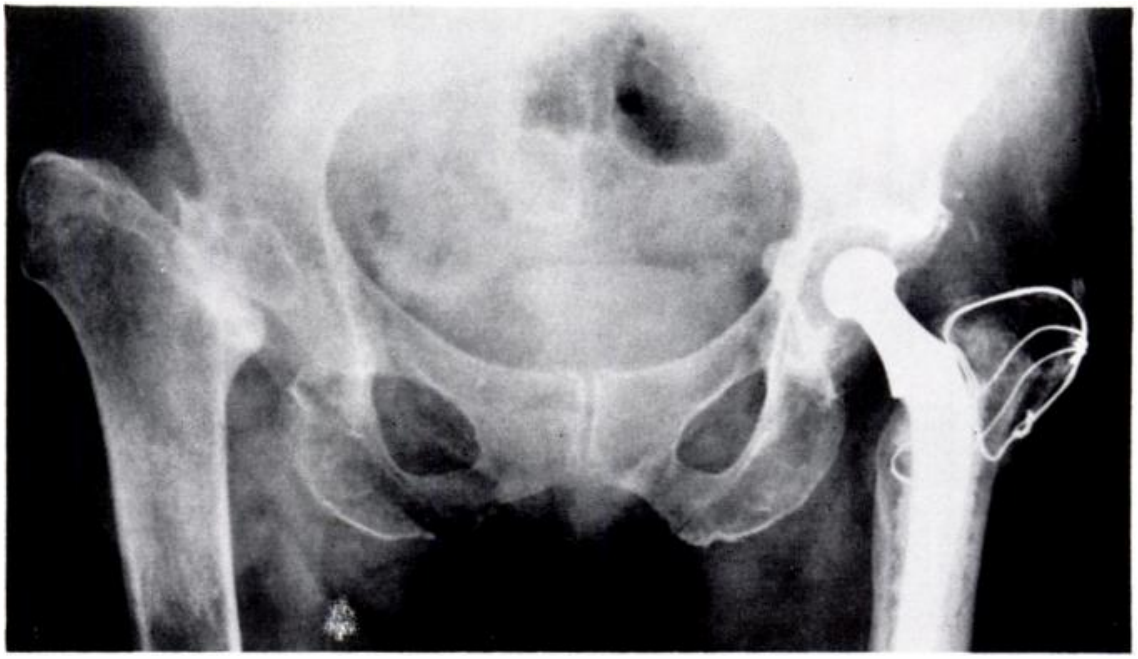

FiG. 11

Figure 10-Bilateral pseudarthrosis of the hips. Figure 11-The same case after conversion of the left side into a low-friction arthroplasty. A similar operation was later carried out on the right side, again with a gratifying result.

five other cases of embolism (2.4 per cent), giving a total incidence of fatal and non-fatal embolism of 3.2 per cent.

Deep venous thrombosis - There were seven cases of deep venous thrombosis. In the early years of this study anticoagulant therapy using Dindevan was practised, but later this was 
stopped and exercises to improve the haemodynamics of venous return became the main preventive measure.

Death from causes other than pulmonary embolism-Two deaths were proved at necropsy to be due to myocardial infarction and to a cerebrovascular accident. This makes the postoperative mortality from all causes 1.9 per cent.

Non-union of the greater trochanter-Eight patients ( 3.7 per cent) had non-union or fibrous union of the greater trochanter. Only one case can be considered a failure because it was combined with a sensation of subluxation of the hip, though the symptoms were not sufficient to indicate further operation. The remaining seven patients when lying on the side could abduct the leg against gravity at least to the horizontal, and in most cases above that.

Dislocation-There were no post-operative dislocations in this series. Two patients, however, developed a sensation of subluxation at 90 degrees of flexion. One had avulsion of the greater trochanter as just mentioned; the other had had a "press-fit" cup inserted without cement (see page 63), and this socket had tilted so that the mouth approached the vertical.

After these difficult reconstructions dislocation is always a possibility, and for this reason a period of three weeks in bed with the legs in abduction is generally advised. If dislocation should occur there is no need for alarm, because reduction can easily be obtained by traction under anaesthesia combined with a lateral pull. A further period of three weeks in abduction in bed is to be advised to give time for the new capsule to reform. In order to shorten the stay in hospital a plaster hip spica may be considered, but this was rarely used in this series. In all difficult cases permanent stability of the hip is to be expected if a slow regime of rehabilitation is used from the beginning.

Exceptional technical difficulties--There were seven very difficult operations. In three cases the lateral femoral cortex was pierced, but this was recognised and the prosthesis did not emerge; in one case the prosthesis emerged from the cortex; two femurs fractured through screw holes after the removal of osteotomy plates; and in one patient a vacuum drain broke off in the wound.

Wound infections-Eight patients (3.7 per cent) developed wound infections. Four were noted soon after operation while four became manifest after a year or more.

\section{QUALITY OF THE RESULTS}

Conversion after osteotomy-One hundred and twenty-one osteotomies were converted in 116 patients. As for pain, prior to operation 98 per cent had pain on weight-bearing (grade 4 or worse) and 86 per cent had pain at rest (grade 3 or worse). One year after conversion 87 per cent had no pain (grade 6), 9 per cent had only occasional intermittent pain (grade 5) and only one patient had pain at rest (grade 3) (Table I).

As for movement, prior to operation only three of the 121 hips had more than 160 degrees of total movement (grade 5) and 86 per cent less than 100 degrees (grade 3 or worse). After operation all the patients except one had more than 100 degrees (grade 4) and 83 per cent had over 160 degrees (grade 5). No patient lost movement after operation.

Conversion from femoral head prosthesis-Fifty-one failed femoral prostheses were converted in forty-nine patients. As for pain, before operation all the hips except one were painful on weight-bearing (grade 4 ) and 82 per cent had pain at rest (grade 3 or worse). One year after conversion three (6 per cent) still had pain on weight-bearing (grade 4); 23 per cent had slight intermittent discomfort (grade 5); and 71 per cent were completely free from pain (grade 6) (Table II).

As for movement, hips with failed prostheses had a somewhat greater range before operation than hips with other causes of failure. 62.5 per cent had a total range of movement over 100 degrees (grade 4 ) but only 17.5 per cent had more than 160 degrees. After operation 74 per cent of these hips had over 160 degrees of movement (grade 5) and 96 per cent had more than 100 degrees of movement.

VOL. 54 B, NO. 1, FEBRUARY 1972 
Conversion after miscellaneous operations-As for pain, in this group pain on weight-bearing (grade 4) was present in 95 per cent of the patients before operation and 78 per cent had pain at rest (grade 3). After surgery there was no pain in 93 per cent (grade 6), the residue of 7 per cent of patients having only intermittent pain (grade 5) (Table III).

TABLE I

Results OF CONVERSION OF 121 OSTEOTOMIES

\begin{tabular}{|c|c|c|c|c|c|c|}
\hline \multicolumn{7}{|c|}{ Pain } \\
\hline Grade & 1 & 2 & 3 & 4 & 5 & 6 \\
\hline Before operation & $2 \%$ & $\begin{array}{l}19 \\
15 \%\end{array}$ & $\begin{array}{l}84 \\
69^{\circ} \circ\end{array}$ & $\begin{array}{l}14 \\
12^{\circ}\end{array}$ & 0 & $\frac{2}{2} \circ$ \\
\hline At 1 year. & 0 & 0 & $1 \%$ & $\begin{array}{l}4 \\
3^{\circ}\end{array}$ & $11 \%$ & $\begin{array}{l}105 \\
87^{\circ}\end{array}$ \\
\hline \multicolumn{7}{|c|}{ Movement } \\
\hline Grade & 1 & 2 & 3 & 4 & 5 & 6 \\
\hline Before operation & $\begin{array}{l}44 \\
36.5 \%\end{array}$ & $\begin{array}{l}33 \\
27 \%\end{array}$ & $\begin{array}{l}28 \\
23^{\circ}\end{array}$ & $\begin{array}{l}13 \\
11 \%\end{array}$ & $\begin{array}{l}3 \\
2.5 \%\end{array}$ & 0 \\
\hline At 1 year. & 0 & 0 & $1 \%$ & $\begin{array}{l}19 \\
16^{\circ}\end{array}$ & $\begin{array}{l}62 。 \\
51^{\circ} 。\end{array}$ & $\begin{array}{c}39 \\
32^{\circ}\end{array}$ \\
\hline
\end{tabular}

TABLE II

Results of Conversion of Fifty-one Femoral Head Prostheses

\begin{tabular}{|c|c|c|c|c|c|c|}
\hline \multicolumn{7}{|c|}{ Pain } \\
\hline Grade & 1 & 2 & 3 & 4 & 5 & 6 \\
\hline Before operation & $2 \%$ & $\begin{array}{l}10 \\
20^{\circ}\end{array}$ & $\begin{array}{l}30 \\
58 \%\end{array}$ & $\stackrel{8}{16^{\circ}}$ & 0 & 20 \\
\hline At 1 year & 0 & 0 & 0 & $\begin{array}{l}3 \\
6^{\circ} 。\end{array}$ & $23 \%$ & $36 \%$ \\
\hline \multicolumn{7}{|c|}{ Movement } \\
\hline Grade & 1 & 2 & 3 & 4 & 5 & 6 \\
\hline Before operation & $2 \%$ & $\begin{array}{r}5 \\
10 \%\end{array}$ & $23.5^{\circ}$ & 23 & $\begin{array}{c}8 \\
15.5 \%\end{array}$ & $2 \%$ \\
\hline At 1 year. & 0 & $2 \%$ & $2 \%$ & $\begin{array}{l}11 \\
22^{\circ}\end{array}$ & $22 \%$ & $\begin{array}{l}16 \\
31 \%\end{array}$ \\
\hline
\end{tabular}

As for movement, before surgery only three (6 per cent) of patients had more than 160 degrees of movement and 49 per cent had less than 60 degrees (grade 2). In 29 per cent the hip was essentially ankylosed. After conversion 84 per cent had more than 160 degrees of movement.

\section{FUNCTION OF WALKING}

In this series of 203 patients there were only fifty with unilateral hip conditions who were physically normal in other respects related to gait and who were therefore suitable for 
TABLE III

Results of Conversion of Forty-five Miscellaneous Operations

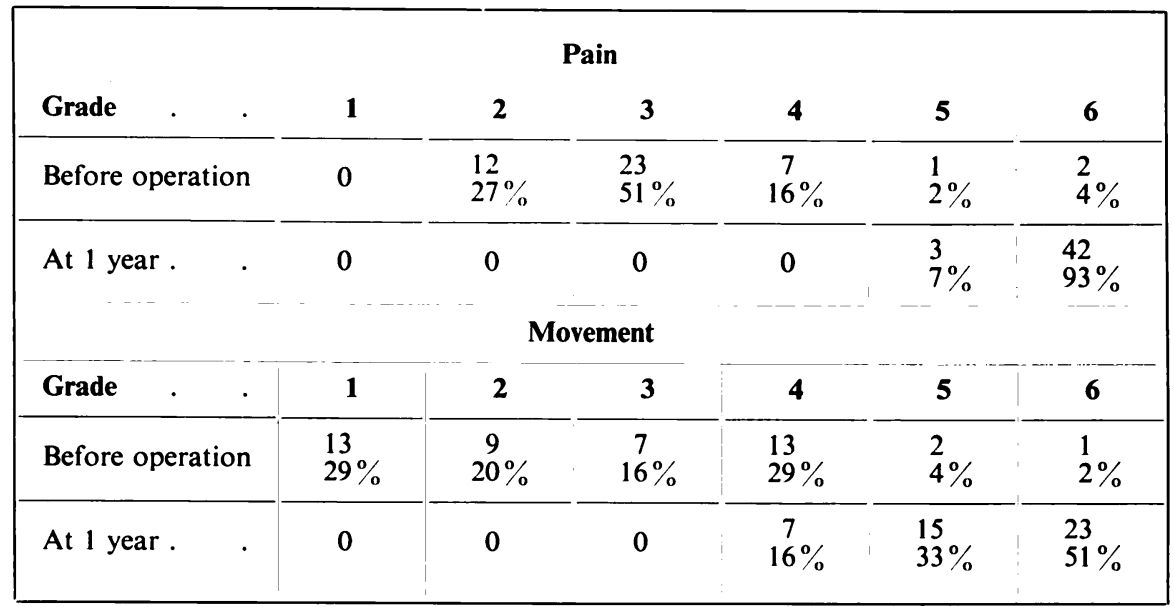

TABLE IV

Total Results

\begin{tabular}{|c|c|c|c|c|c|c|}
\hline \multicolumn{7}{|c|}{ Pain } \\
\hline Grade & 1 & 2 & 3 & 4 & 5 & 6 \\
\hline Before operation & $\begin{array}{l}4 \\
2 \%\end{array}$ & $\begin{array}{l}41 \\
19 \%\end{array}$ & $\begin{array}{l}137 \\
63 \%\end{array}$ & $\begin{array}{l}29 \\
13.5 \%\end{array}$ & $\begin{array}{l}1 \\
0.5 \%\end{array}$ & $\begin{array}{l}5 \\
2 \%\end{array}$ \\
\hline At 1 year. & 0 & 0 & $\begin{array}{l}1 \\
0.5 \%\end{array}$ & $7 \%$ & $\begin{array}{l}26 \\
12 \%\end{array}$ & $\begin{array}{l}183 \\
84.5 \%\end{array}$ \\
\hline At 3 years & 0 & $2.5 \%$ & $2.5 \%$ & $\begin{array}{l}3 \\
8 \%\end{array}$ & $\begin{array}{l}4 \\
11 \%\end{array}$ & $\begin{array}{l}28 \\
76 \%\end{array}$ \\
\hline At 5 years & 0 & 0 & $5 \%$ & $2 \%$ & $\begin{array}{l}4 \\
17 \%\end{array}$ & $\begin{array}{l}16 \\
69 \%\end{array}$ \\
\hline \multicolumn{7}{|c|}{ Movement } \\
\hline Grade $\quad$. & 1 & 2 & 3 & 4 & 5 & 6 \\
\hline Before operation & $\begin{array}{l}59 \\
27 \%\end{array}$ & $\begin{array}{l}47 \\
21.5 \%\end{array}$ & $\begin{array}{l}47 \\
21 \cdot 5 \%\end{array}$ & $\begin{array}{l}49 \\
23.5 \%\end{array}$ & $\begin{array}{l}13 \\
6 \%\end{array}$ & $\begin{array}{l}2 \\
1 \%\end{array}$ \\
\hline At 1 year & 0 & $\begin{array}{l}1 \\
0.5 \%\end{array}$ & $\begin{array}{l}2 \% \\
1 \%\end{array}$ & $\begin{array}{l}37 \\
17 \%\end{array}$ & $\begin{array}{l}99 \\
45.5 \%\end{array}$ & $\begin{array}{l}78 \\
36 \%\end{array}$ \\
\hline At 3 years & 0 & 0 & 0 & $\begin{array}{c}82 \% \\
22 \%\end{array}$ & $\begin{array}{l}12 \% \\
32 \%\end{array}$ & $\begin{array}{l}17 \\
46 \%\end{array}$ \\
\hline At 5 years & 0 & 0 & 0 & $\begin{array}{c}6 \\
26 \%\end{array}$ & $\begin{array}{c}52 \% \\
22 \%\end{array}$ & $\begin{array}{l}12 \\
52 \%\end{array}$ \\
\hline
\end{tabular}

VOL. 54 B, NO. 1, FEBRUARY 1972 
assessment as regards walking (category "A" patients-page 62). Only seven of the fifty were over three years from operation and the results are therefore those recorded at one year. Before operation nearly all these patients were severely restricted, 96 per cent walking less than half a mile with or without one or two sticks. One year after operation 78 per cent were unlimited in their activity, although 12 per cent had a slight limp.

As regards walking aids, 74 per cent needed some type of aid before operation, while only 6 per cent needed one after operation. A gross limp was present in 76 per cent of the patients before operation but only one patient ( 2 per cent) had a gross limp after operation.

\section{THE QUALITY OF THE TOTAL SERIES}

Low-friction arthroplasty has been used extensively to salvage failed operations only recently, so that most of the patients in this series had been operated upon less than three years previously. There were thirty-seven patients available for three-year and twenty-three patients for five-year review. The quality of the function of walking for the whole series could not be assessed, apart of course from fifty patients already mentioned. The total quality of the series therefore relates to pain and range of movement.

Before operation 97.5 per cent of patients had pain on weight-bearing (grade 4) and 84 per cent had pain at rest (grade 3). Included in the series were six patients with both hips very stiff but little or no pain.

After one year 84.5 per cent had no pain (grade 6) and 12 per cent had only minimal pain (grade 5). Seven patients ( 3 per cent) had pain on weight-bearing and one ( 0.5 per cent) had pain at rest.

Eight patients ( 3.5 per cent) had pain on weight-bearing (grade 4$)$ one year after operation and count as mechanical failures. Two of these may be excused in that one had an experimental design of cup that became loose, and one had a tilted "press-fit" cup used without cement, a technique abandoned in 1965. This leaves six patients with disappointing results for which no excuse can be offered. Four patients with pain at one year still had pain three and five years after operation. It must be emphasised, however, that no patient suffered more pain than before operation.

Mobility-No patient lost movement after conversion. Only three patients ( 1.5 per cent $)$ had less than 100 degrees of total movement; all three started with less than 30 degrees. Two of these patients developed ectopic bone but gained 50 and 60 degrees nevertheless. The third patient had had a firm fibrous ankylosis but gained 80 degrees.

\section{INFECTION}

The infection rate in this series was remarkably similar to that encountered in the threeyear period from November 1962 to December 1965 which was the subject of a previous report on primary interventions (page 61). Nevertheless, this infection rate was approximately double that for primary operations during the same period. After 1965 more sophisticated aseptic techniques were employed and one presumes that without them the infection rate for revision might have been as high as 7 per cent.

It is interesting to note that at the time of operation, in a second and sometimes a third intervention, infection was suspected and material for cultures and histology was taken in fifty-five cases. Thirteen of these ( 23.6 per cent) were positive (nine cases of coagulase negative staphylococcus; one of staphylococcus aureus; one of mixed coliforms and staphylococci; one of coliforms; and one of haemolytic streptococci). It is remarkable that only one of these hips has so far developed a definite deep infection, and in only one is an infection suspected on radiological grounds. Both patients had had coagulase negative staphylococci. 


\section{CONCLUSIONS}

1. Two hundred and seventeen low-friction arthroplasties performed between November 1962 and April 1969 in 203 patients with failed previous operations have been analysed.

2. The technical details of operation in relation to these conversion problems have been outlined.

3. The quality of the results in relation to pain, mobility and ability to walk has been assessed before operation and one year afterwards, with small numbers at three and five years.

4. Pain was completely relieved or was minimal in 96.3 per cent of the patients, and in no case was the pain worse.

5. The total range of movement was 100 degrees or more in 98.5 per cent. No hip lost movement after conversion.

6. The failures were principally due to infection and to technical difficulties. There were no mechanical failures without a technical or radiological explanation.

7. Low-friction arthroplasty is an excellent salvage procedure, especially for failed cup arthroplasty.

\section{REFERENCE}

Merle D'Aubigné, R., and Postel, M. (1954): Functional Results of Hip Arthroplasty with Acrylic Prosthesis. Journal of Bone and Joint Surgery, 36-A, 451. 